\title{
PERSEPSI KONSUMEN TERHADAP PRODUK SEPATU OLAHRAGA DI SPORT STATION MEGAMALL DENGAN MENGGUNAKAN ANALISIS MULTIDIMENSIONAL SCALING
}

\author{
Triana J. Masuku' ${ }^{1)}$ Marline S. Paendong1)， Yohanes A.R. Langi ${ }^{1)}$ \\ ${ }^{1)}$ Program Studi Matematika FMIPA UNSRAT, Manado \\ e-mail: trymasuku@yahoo.com; marline_paendong@yahoo.com; yarlangi@gmail.com
}

\begin{abstract}
ABSTRAK
Analisis Multidimensional Scaling (MDS) adalah salah satu analisis multivariat yang berhubungan dengan penempatan beberapa objek pada suatu peta multidimensional yang ditentukan berdasarkan kemiripan. Tujuan dari penelitian ini adalah untuk mendeskripsikan persepsi konsumen terhadap produk sepatu olahraga dan mengetahui kemiripan antara sepatu olahraga di Sport Station Megamall. Objek penelitiannya adalah sepatu olahraga Converse, Adidas, Diadora, Nike, Puma, Reebok dan New Balance. Dengan menggunakan Quota Sampling, jumlah responden yang dicari untuk masing-masing sepatu olahraga adalah 20 responden sehingga total respondennya adalah 140 orang. Hasilnya menunjukkan bahwa pada peta MDS sepatu olahraga Adidas dan Nike memiliki jarak yang saling berdekatan sehingga dikatakan keduanya mirip dibandingkan dengan sepatu olahraga lainnya. Keduanya mirip untuk atribut bahan dan model sepatu.
\end{abstract}

Kata kunci: Analisis Multidimensional Scaling, Sepatu Olahraga

\section{PERCEPTION OF THE CONSUMERS ABOUT SPORT SHOES PRODUCTS IN SPORT STATION OF MEGAMALL WITH USING ANALYSIS OF MULTIDIMENSIONAL SCALING}

\begin{abstract}
Analysis of Multidimensional Scaling (MDS) is one of the multivariate analysis that related to placement some objects in a multidimensional map based on similarity. The purpose of this research is to describe the perception of consumers about sport shoes and know similarities between sport shoes in Sport Station of Megamall. The data in this research are Converse, Adidas, Diadora, Nike, Puma, Reebok and New Balance sport shoes. With using quota sampling, respondents for each sport shoes are 20 so the total are 140 respondents. The result shows that Adidas and Nike on MDS map have distance is near each other so both of them are called same than the others. Their similarities are material and display of shoes atributes.
\end{abstract}

Keywords: Multidimensional Scaling Analysis, Sport Shoes

\section{PENDAHULUAN}

Dunia industri saat ini telah mengalami perkembangan yang sangat pesat sehingga melahirkan persaingan antar perusahaan menjadi semakin tinggi. Hal ini menyebabkan semua perusahaan industri berusaha menghasilkan produk terbaiknya agar dapat menguasai pasar. Seiring dengan meningkatnya jumlah penduduk, taraf hidup, bergesernya gaya hidup dan semakin sadarnya orang akan kesehatan, membuat banyak orang meluangkan waktu untuk dapat berolahraga baik di dalam ruangan maupun di luar ruangan. Semakin banyak orang yang ingin berolahraga menyebabkan permintaan terhadap atribut-atribut olahraga juga mengalami peningkatan. Atribut olahraga yang paling diburu konsumen adalah sepatu olahraga.

Salah satu toko yang menjual berbagai macam sepatu olahraga adalah Sport Station, dimana produk yang dijual adalah produk-produk impor berkualitas yang banyak diminati orang. Produk-produk yang terdapat di Sport Station yaitu Converse, 
Adidas, Diadora, Nike, Puma, Reebok dan New Balance. Jenis-jenis sepatu olahraganya antara lain, sepatu olahraga sepakbola, futsal, tenis, basket, golf, running dan bulutangkis.

Penelitian ini dilaksanakan untuk mengetahui persepsi konsumen terhadap produk sepatu olahraga dengan menggunakan analisis Multidimensional Scaling (MDS). Multidimensional Scaling (MDS) merupakan salah satu alat analisis multivariat yang berhubungan dengan penempatan beberapa objek pada suatu peta multidimensional yang ditentukan oleh konsumen berdasarkan proximities (nilai kedekatan) antara beberapa objek tersebut.

\section{Analisis Multidimensional Scaling (MDS)}

Defenisi sederhana dari

Multidimensional Scaling adalah pencarian ruang dimensi yang kecil (pada umumnya menggunakan euklid) yang dapat menyajikan objek-objek sedemikian, sehingga jarak antar objek pada ruang dimensi tersebut sesuai dengan jarak asli antar objek yang diamati. Kegunaan MDS adalah mentransformasi tanggapan konsumen melalui kemiripan atau preferensinya kedalam jarak yang dipresentasikan pada ruang dimensi. Jika objek A dan B dipandang oleh konsumen sebagai objek yang mirip satu sama lain dibanding pasangan objek-objek yang lain, MDS akan menempatkan A dan B pada jarak yang dekat dibanding jarak pasangan objekobjek lainnya dalam ruang multidimensi. Dari definisi tersebut, kegunaan Multidimensional Scaling adalah untuk menyajikan objek-objek secara visual berdasarkan kemiripan yang dimiliki. Selain itu, kegunaan lain dari teknik ini ialah mengelompokkan objek-objek yang memiliki kemiripan dilihat dari berapa peubah yang dianggap mampu mengelompokkan objekobjek tersebut (Mattjik dan Sumertajaya, 2011).

Analisis data MDS digunakan nilainilai yang menggambarkan tingkat kemiripan atau tingkat ketakmiripan antar objek yang sering disebut proximity (Ginanjar, 2008).

Proximity dibagi atas dua yaitu :

1. Similarity (kemiripan) yaitu jika semakin kecil nilai jaraknya, menunjukkan bahwa objeknya lebih mirip.
2. Dissimilarity (ketakmiripan) yaitu jika semakin besar nilai jaraknya, menunjukkan bahwa objeknya semakin tak mirip.

MDS dibagi menjadi dua jenis, yaitu MDS metrik (data bertipe ordinal) dan MDS non-metrik (data bertipe interval dan rasio) (Ginanjar, 2008).

Untuk mengetahui tingkat ketidakcocokan output dengan keadaan sebenarnya digunakan fungsi STRESS (Standardized Residual Sum of Square) sebagai berikut:

$$
\text { Stress }=\sqrt{\frac{\sum_{t, u}\left(d_{t u}-\hat{d}_{t u}\right)^{2}}{\sum_{t, u}\left(d_{t u}-\bar{d}\right)^{2}}}
$$

Dengan ketentuan nilai sebagai berikut :

Tabel 1. Nilai Kesesuaian Fungsi STRESS

\begin{tabular}{|c|c|}
\hline STRESS $(\%)$ & Kesesuaian \\
\hline$>20$ & Buruk \\
\hline $10-20$ & Cukup \\
\hline $5,1-10$ & Baik \\
\hline $2,5-5$ & Sangat Baik \\
\hline$<2,5$ & Sempurna \\
\hline
\end{tabular}

\section{METODOLOGI PENELITIAN}

\section{Data Penelitian}

Pengambilan data dilakukan pada bulan Mei-Agustus 2014. Data yang digunakan adalah data primer yang diperoleh dari kuesioner. Responden dalam penelitian ini adalah konsumen yang pernah membeli sepatu olahraga di Sport Station Megamall. Jumlah respondennya 140 responden, dimana dari setiap objek (sepatu olahraga) dicari masing-masing 20 responden.

Formulasi definisi operasional dalam penelitian ini menggunakan teknik skoring skala Likert yaitu pertanyaan-pertanyaan yang memberikan lima alternatif pilihan yang diberi skor sebagai berikut :

1. Sangat setuju

2. Setuju

3. Kurang setuju

4. Tidak setuju

5. Sangat tidak setuju diberi skor 5 diberi skor 4 diberi skor 3 diberi skor 2 diberi skor 1 


\section{Objek dan Peubah Penelitian}

Tabel 2. Objek Penelitian

\begin{tabular}{|c|c|}
\hline Kode & $\begin{array}{c}\text { Nama Merek } \\
\text { Sepatu Olahraga }\end{array}$ \\
\hline 1 & Converse \\
\hline 2 & Adidas \\
\hline 3 & Diadora \\
\hline 4 & Nike \\
\hline 5 & Puma \\
\hline 6 & Reebok \\
\hline 7 & New Balance \\
\hline
\end{tabular}

Tabel 3. Peubah-peubah yang Diamati

\begin{tabular}{|c|c|}
\hline Peubah & Defenisi \\
\hline $\mathrm{X} 1$ & Harga sepatu terjangkau \\
\hline $\mathrm{X} 2$ & $\begin{array}{l}\text { Bahan sepatu berkualitas } \\
\text { sangat baik }\end{array}$ \\
\hline $\mathrm{X} 3$ & Sepatu tahan lama \\
\hline $\mathrm{X} 4$ & $\begin{array}{l}\text { Model yang disediakan } \\
\text { bervariasi }\end{array}$ \\
\hline $\mathrm{X} 5$ & Warna sepatu menarik \\
\hline X6 & $\begin{array}{l}\text { Tampilan sepatu sesuai tren } \\
\text { masa kini }\end{array}$ \\
\hline $\mathrm{X} 7$ & $\begin{array}{l}\text { Sepatu yang ditawarkan } \\
\text { sesuai kebutuhan }\end{array}$ \\
\hline $\mathrm{X} 8$ & $\begin{array}{l}\text { Sepatu terasa ringan saat } \\
\text { dipakai }\end{array}$ \\
\hline X9 & $\begin{array}{l}\text { Sepatu terasa nyaman saat } \\
\text { dipakai }\end{array}$ \\
\hline $\mathrm{X} 10$ & $\begin{array}{l}\text { Sepatu aman dipakai saat } \\
\text { berolahraga }\end{array}$ \\
\hline $\mathrm{X} 11$ & $\begin{array}{l}\text { Sepatu yang dibeli penting } \\
\text { untuk pergaulan }\end{array}$ \\
\hline $\mathrm{X} 12$ & $\begin{array}{l}\text { Bagian sepatu mudah } \\
\text { dibersihkan }\end{array}$ \\
\hline $\mathrm{X} 13$ & Stok sepatu selalu ada \\
\hline $\mathrm{X} 14$ & $\begin{array}{l}\text { Merasa puas dengan sepatu } \\
\text { yang dibeli }\end{array}$ \\
\hline $\mathrm{X} 15$ & $\begin{array}{l}\text { Popularitas merek sepatu } \\
\text { sangat terkenal }\end{array}$ \\
\hline $\mathrm{X} 16$ & $\begin{array}{l}\text { Merek pernah memberikan } \\
\text { diskon }\end{array}$ \\
\hline $\mathrm{X} 17$ & $\begin{array}{l}\text { Sepatu memiliki Brand } \\
\text { ambassador (ikon merek) } \\
\text { yang terkenal }\end{array}$ \\
\hline $\mathrm{X} 18$ & $\begin{array}{l}\text { Iklan dari merek sepatu } \\
\text { selalu menarik perhatian }\end{array}$ \\
\hline X19 & $\begin{array}{l}\text { Sepatu yang dibeli } \\
\text { menunjukkan jati diri } \\
\text { seseorang }\end{array}$ \\
\hline $\mathrm{X} 20$ & $\begin{array}{l}\text { Sepatu dari merek tersebut } \\
\text { menjadi favorit }\end{array}$ \\
\hline
\end{tabular}

\section{Tahapan Penelitian}

1. Pengumpulan Data

2. Melakukan uji validitas dan reliabilitas kuesioner (dengan software SPSS 19)

3. Membuat analisis deskriptif kuantitatif (dengan software Microsoft Excel)

4. Mengubah data kuesioner yang berbentuk ordinal menjadi interval dengan cara Method of Successive Interval (dengan software Microsoft Excel)

5. Melihat kenormalan data setelah diubah menjadi bentuk interval (dengan software SPSS 19)

6. Analisis MDS digunakan untuk melihat kemiripan atau ketakmiripan antara produk sepatu olahraga berdasarkan penilaian konsumen diolah menggunakan program SPSS 19 dengan langkah-langkah sebagai berikut :

a) Masukkan data pada Data View.

b) Pilih Analyze > Scale. Pilih Multidimensional Scaling (ALSCAL).

c) Pindahkan semua variabel ke kolom Variables.

d) Pada bagian Distances centang Create Distances from Data, kemudian klik Measure. Pada pilihan Measure centang Interval, pilih Euclidean Distance, kemudian klik Continue.

e) Model : Level of Measurement, pilih Interval; Scaling Model, pilih Euclidean distance; Conditionality, pilih Matrix; Dimensions untuk Minimum dan Maximum isikan angka 2. Kemudian tekan Continue.

f) Options : pilih Data Matrix, kemudian tekan Continue.

g) Klik $O K$ untuk diproses

\section{HASIL DAN PEMBAHASAN}

\section{Analisis Deskriptif}

Data penilaian konsumen terhadap produk sepatu olahraga diolah untuk mendapatkan deskripsinya. Konsumen menilai bahwa untuk sepatu olahraga Adidas memiliki nilai rata-rata tertinggi pada atribut sepatu tahan lama (X3), tampilan sepatu sesuai tren masa kini (X6), konsumen merasa puas dengan sepatu yang dibeli (X14), 
popularitas merek sepatu sangat terkenal (X15) dan sepatu yang dibeli menunjukkan jati diri seseorang (X19). Sepatu olahraga Converse unggul pada atribut stok sepatu selalu ada (X13) dan merek sepatu menjadi favorit (X20). Sepatu olahraga Nike unggul pada atribut bahan sepatu berkualitas sangat baik (X2), sepatu tahan lama (X3), model yang disediakan bervariasi (X4), warna sepatu menarik (X5), tampilan sepatu sesuai tren masa kini (X6), sepatu aman dipakai berolahraga (X10), sepatu yang dibeli penting untuk pergaulan (X11), popularitas merek sangat terkenal (X15), sepatu memiliki Brand Ambassador terkenal (X17) dan iklan dari merek selalu menjadi perhatian (X18). Sepatu olahraga Diadora unggul pada atribut harga terjangkau (X1) dan sepatu nyaman dipakai berolahraga (X9). Sepatu olahraga Puma unggul untuk atribut bagian sepatu mudah dibersihkan (X12) dan konsumen merasa puas dengan sepatu yang dibeli (X14). Sedangkan untuk sepatu olahraga Reebok unggul di atribut sepatu yang ditawarkan sesuai kebutuhan (X7), sepatu terasa ringan dipakai (X8) dan merek pernah memberikan diskon (X16).

\section{Analisis Multidimensional Scaling (MDS)}

Data penilaian konsumen diintervalkan dan diuji kenormalannya. Hasil Penelitian Multidimensional Scaling ini memiliki model kelayakan yang baik dengan nilai RSQ sebesar $88,11 \%$ dan nilai STRESS sebesar 13\%. Berikut Stimulus Coordinates dari ketujuh sepatu olahraga :

Tabel 4. Stimulus Coordinates

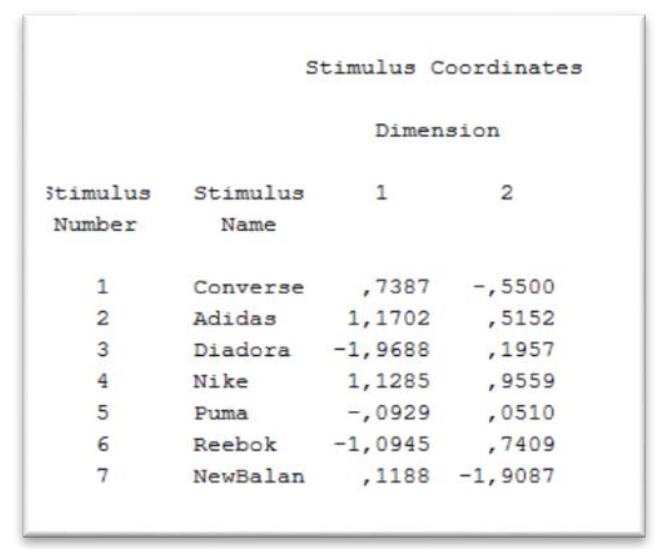

Dari koordinat diatas terbentuk peta posisi untuk ketujuh sepatu olahraga tersebut.

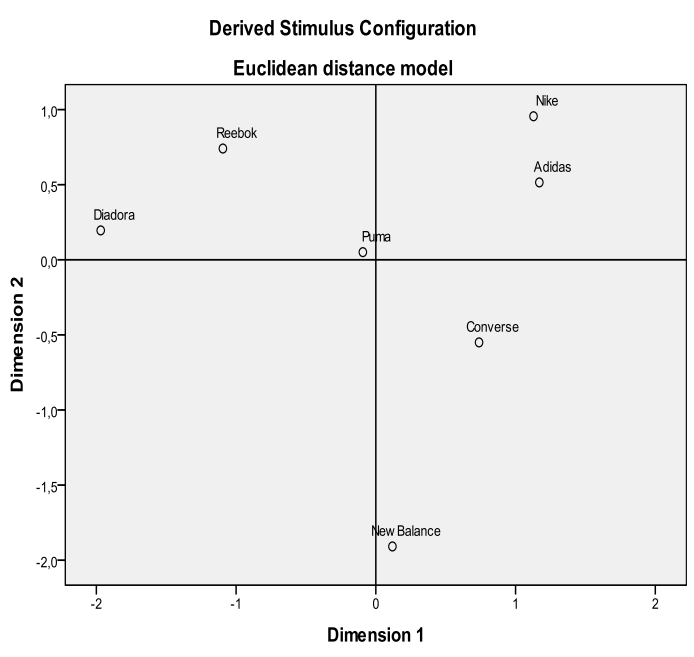

Gambar 1. Peta Posisi Sepatu Olahraga

Gambar diatas adalah peta MDS untuk produk sepatu olahraga. Terlihat bahwa sepatu olahraga yang berada pada kuadran yang sama yaitu Adidas dengan Nike, Converse dengan New Balance, selanjutnya Diadora, Reebok dengan Puma. Namun berdasarkan posisi jaraknya hanya pasangan Adidas-Nike yang jaraknya yang paling berdekatan, sehingga dapat dikatakan keduanya mirip.

Tabel 5. Selisih Nilai Karakteristik antara Sepatu Olahraga Adidas dan Nike untuk Dimensi 1.

\begin{tabular}{|c|r|r|r|}
\hline \multirow{2}{*}{ Peubah } & \multicolumn{3}{|c|}{ Dimensi 1 } \\
\cline { 2 - 4 } & Adidas & Nike & \multicolumn{1}{c|}{ Selisih } \\
\hline X1 & 1,8022 & 2,5038 & $-0,7016$ \\
\hline X2 & $-0,2444$ & $-0,2731$ & 0,0287 \\
\hline X3 & $-0,5534$ & $-0,6948$ & 0,1414 \\
\hline X4 & $-1,1826$ & $-1,2307$ & 0,0481 \\
\hline X5 & $-0,8055$ & $-1,3309$ & 0,5254 \\
\hline X6 & $-1,3811$ & $-1,2675$ & $-0,1136$ \\
\hline X7 & $-0,9598$ & 0,1044 & $-1,0642$ \\
\hline X8 & $-0,8402$ & 0,1958 & $-1,036$ \\
\hline X9 & $-0,5605$ & $-0,1618$ & $-0,3987$ \\
\hline X10 & $-0,2468$ & $-0,6424$ & 0,3956 \\
\hline X11 & $-0,7127$ & $-0,6991$ & $-0,0136$ \\
\hline X12 & 2,2067 & 2,1238 & 0,0829 \\
\hline X13 & 1,0641 & 1,7744 & $-0,7103$ \\
\hline X14 & $-0,4827$ & 0,8646 & $-1,3473$ \\
\cline { 2 - 3 }
\end{tabular}




\begin{tabular}{|r|r|r|r|}
\cline { 3 - 3 } X15 & $-0,9121$ & $-1,0021$ & 0,09 \\
\hline X16 & 1,0691 & 2,6676 & $-1,5985$ \\
\hline X17 & $-0,3601$ & $-0,7821$ & 0,422 \\
\hline X18 & 0,3783 & $-0,0197$ & 0,398 \\
\hline X19 & 0,0155 & 1,3573 & $-1,3418$ \\
\hline X20 & 0,1365 & $-0,6451$ & 0,7816 \\
\hline
\end{tabular}

Tabel 6. Selisih Nilai Karakteristik antara Sepatu Olahraga Adidas dan Nike untuk Dimensi 2.

\begin{tabular}{|c|r|r|r|}
\hline \multirow{2}{*}{ Peubah } & \multicolumn{3}{|c|}{ Dimensi 2 } \\
\cline { 2 - 4 } & \multicolumn{1}{|c|}{ Adidas } & \multicolumn{1}{c|}{ Nike } & \multicolumn{1}{c|}{ Selisih } \\
\hline X1 & $-0,9972$ & 1,18 & $-2,1772$ \\
\hline X2 & 0,1332 & 0,6719 & $-0,5387$ \\
\hline X3 & 0,5729 & 0,8254 & $-0,2525$ \\
\hline X4 & $-0,3977$ & $-0,4405$ & 0,0428 \\
\hline X5 & 0,7728 & 0,5143 & 0,2585 \\
\hline X6 & 0,2303 & 0,3154 & $-0,0851$ \\
\hline X7 & $-0,6703$ & $-1,1453$ & 0,475 \\
\hline X8 & $-0,6628$ & 0,3704 & $-1,0332$ \\
\hline X9 & $-0,937$ & 0,6669 & $-1,6039$ \\
\hline X10 & $-1,5066$ & 0,6611 & $-2,1677$ \\
\hline X11 & 0,1089 & $-0,7704$ & 0,8793 \\
\hline X12 & $-1,0482$ & 0,9718 & $-2,02$ \\
\hline X13 & $-1,2878$ & 0,7491 & $-2,0369$ \\
\hline X14 & 0,5782 & 1,0314 & $-0,4532$ \\
\hline X15 & 0,292 & 0,4064 & $-0,1144$ \\
\hline X16 & $-1,4463$ & 0,0517 & $-1,498$ \\
\hline X17 & $-0,8574$ & 0,885 & $-1,7424$ \\
\hline X18 & $-1,6032$ & $-1,6778$ & 0,0746 \\
\hline X19 & 0,9484 & 0,6182 & 0,3302 \\
\hline X20 & 0,9639 & 0,0481 & 0,9158 \\
\hline & & & \\
\hline
\end{tabular}

Setelah diperoleh selisih untuk masing-masing karakteristik, dengan menggunakan Size Difference dapat ditentukan karakteristik mana saja yang memiliki tingkat kemiripan. Size Difference nilainya berkisar $0-1$. Apabila selisih antara Adidas dan Nike semakin mendekati angka 0 maka dinyatakan mirip. Berdasarkan Stimulus Coordinates, diperoleh 7 karakteristik yang mirip antara sepatu olahraga adidas dan nike yaitu bahan sepatu berkualitas sangat baik (X2), sepatu tahan lama (X3), model sepatu bervariasi (X4), warna sepatu menarik (X5),

tampilan sepatu yang sesuai tren masa kini (X6), popularitas merek sepatu sangat terkenal (X15), dan iklan yang menarik perhatian (X18).

\section{KESIMPULAN}

1. Persepsi konsumen menyatakan bahwa sepatu olahraga yang atribut-atibutnya disukai adalah sepatu olahraga Nike, sedangkan yang kurang adalah sepatu olahraga New Balance.

2. Sepatu olahraga yang memiliki kemiripan adalah sepatu olahraga Adidas dan Nike. Keduanya mirip pada atribut bahan dan tampilan sepatu.

\section{DAFTAR PUSTAKA}

Dillon, W. R. Matthew, G. 1984. Multivariate Analysis: Methods and Aplication. John Willey and Sons Inc, New York.

Ginanjar, I. 2008. Aplikasi Multidimensional Scaling (MDS) untuk Peningkatan Pelayanan Proses Belajar Mengajar (PBM). Staf Pengajar Jurusan Statistika FMIPA UNPAD, Bandung.

Mattjik, A. A. dan I Made Sumertajaya. 2011. Sidik Peubah Ganda : dengan Menggunakan SAS. IPB, Bogor.

Simamora, B. 2005. Analisis Multivariat Pemasaran. PT Gramedia Pustaka Utama. Jakarta. 